\title{
Multidisciplinary approach in the treatment of women in Climacteria: Mind and body connection
}

\author{
Andrea BF Maiolino ${ }^{1}$, Glauber P Florencio ${ }^{1}$, Tiago Saramento ${ }^{1}$, Renato R Silva ${ }^{1}$ and Denise VD deB Röder ${ }^{1,2 *}$ \\ ${ }^{1}$ Health Sciences Postgraduate Program, Faculty of Medicine, Federal University of Uberlândia, Brazil \\ ${ }^{2}$ Institute of Biomedical Sciences, Federal University of Uberlândia, Brazil
}

\section{Summary}

Climacteric is defined as the end of reproductive life and the beginning of aging, characterized by the decline in ovarian functions and consequent hormonal changes. The characteristic symptoms are changes in the central nervous system, genito-urinary tract, cardiovascular system, skin and bones. The climacteric is influenced by social, cultural, and economic factors, which will determine the way women experience it and, therefore, it is necessary to seek a whole balance, combining hormonal balance, nutrition, body and mind. In this aspect, the search for alternative methods has grown, seeking to understand the climacteric woman in a holistic way, individualizing her needs and making available measures to promote health, either through the improvement of eating habits, physical activity and mental health. Integrative medicine is an area of medicine that proposes to have a differentiated look from physical health to treat the physical, mental, and emotional health of the patient in a more humane and less interventionist way. The main focus of this specialty is to eliminate behaviours or harmful habits that cause an imbalance in the body and result in the appearance of chronic diseases. We describe in detail below about the importance for the health of climacteric women the integration between physical, mental, and emotional health so that each patient can enjoy full balance between body and mind, thus it becomes fundamental a systemic look through the multidisciplinary approach enabling the development of new habits that will contribute to the woman through this phase of life with less impact.

Menopause occurs naturally in most women being defined as the end of reproductive life, confirmed when the woman is without menstruation for a period of 12 consecutive months. The average age of menopause is 52 years, which can vary from 40 to 58 years, from the end of the reproductive phase to senility, a period called climacteric [1]. There is a reduction in ovarian function that can lead to a decrease of 17 -beta-estradiol (E2) and other hormones such as androgens and progesterone. The abrupt fall of estrogen levels during menopause can change the adjustment point of the hypothalamus thermoregulation, which leads to vasomotor symptoms, consisting of heat waves and night sweats, besides changes in bone and lipid metabolism [2]. The interaction of estrogen with neurotransmitters including norepinephrine, endogenous opioids, and serotonin are also known to alter the temperature regulation point in the hypothalamus [3].

Hormone replacement therapy (HRT) has been widely discussed in society: media, healthcare professionals and patients [4]. HRT is effective in relieving climacteric symptoms; improves the lipid and lipoprotein profile; prevents cardiovascular diseases and osteoporosis, enabling an improvement in women's quality of life [5]. Hormone therapy is an effective treatment for uncomfortable heat waves, night sweats, but research has raised questions about the safety of hormone therapy, consequently many women have become reluctant to consider hormone therapy as a therapeutic option for their symptoms [6].

In the climacteric period a whole balance is sought, uniting hormonal balance, nutrition, body, and mind [7]. In this period, several are the signs and symptoms observed, ranging from tiredness, indisposition, mood swings, decrease or loss of libido, in addition to physical changes such as loss of hair, weakening of fingernails, change in skin, vaginal dryness [8]. And in the long term, decreased cardiovascular protection and osteoporosis [9]. In this aspect, the search for alternative methods has grown, seeking to understand the climate woman in its entirety, individualizing their needs and providing measures to promote health, either through improvement of eating habits, physical activity, mental health, and after detailed analysis of the clinical picture analyze the possibility of hormone replacement, vitamin and nutrient supplementation with the aim of providing a better quality of life [10]. Through this action, it is possible to provide a space for women's participation in decision-making about their therapeutic planning [11].

At the end of the 1990s, in an attempt to describe a new health model that portrays the integration of the various therapeutic models, rather than simply operating with complementary logic, and that offers integral health care, the term "Integrative Medicine" was created [12]. Integrative Medicine is an area of medicine that aims to have a differentiated look at the physical, mental and emotional health of the patient in a more humane and less interventionist way, having as its premise the patient and medical involvement in a therapeutic partnership [13]. Based on preventive techniques and methods, the specialty's main objective is to act on the causes of diseases, aiming at promoting well-being and quality of life [14]. The integrative medicine approach considers that most complex chronic diseases are preceded by dysfunctions in one or more systems of our organism, resulting from interaction with the environment, lifestyle, emotional factors, and family medical history [15].

${ }^{\star}$ Correspondence to: Denise Von Dolinger de Brito Röder, Health Sciences Postgraduate Program, Faculty of Medicine, Federal University of Uberlândia, Brazil, Tel: 55-34 -3219-8670; E-mail: denise.roder@ufu.br

Key words: climacteric, menopause, integrative medicine, nutrition, physical activity, psychotherapy, multidisciplinary approach, systemic vision

Received: July 14, 2020; Accepted: July 31, 2020; Published: August 03, 2020 
Unlike traditional medicine, which has as its priority to treat the disease or its symptoms, integrative medicine goes further and aims to fight the cause that is causing that problem [16]. For integrative medicine, health is a vital state of mental, physical, social, emotional, and spiritual well-being [14]. The focus of this specialty is to eliminate behaviours or harmful habits that cause disequilibrium in the body and result in the appearance of chronic diseases. The final objective is to promote an integration between physical, mental, and emotional health so that each patient can enjoy full balance between body and mind.

Several studies report that obese women have a higher risk of vasomotor symptoms than non-obese women regardless of race, age, and smoking [17-20]. Smoking is a strong risk factor for heat waves. The tendency of climateric women is to show an increase in their body mass due to endocrine and metabolic changes. Thus, a low-calorie diet, poor in carbohydrates and animal fats that will help maintain weight, control cholesterol levels, triglycerides and glycemia that tend to show deleterious changes should be recommended [21]. The diet should be rich in vegetables and fruits, avoiding industrialized food and frying. Another healthy measure is a higher calcium intake to minimize bone loss caused by hypoestrogenism. The nutritional orientation and its practice will have its benefits enhanced by the practice of physical activity [22].

Sedentarism is increasingly responsible for worsening health conditions for men and women, increasing body mass, worsening levels of cholesterol, glucose, acceleration of bone loss and greater risk for cardiovascular diseases, evidenced by endothelial dysfunction $[23,24]$. Studies have proven that women who exercise regularly lead to weight loss, improved glucose tolerance, reduced total cholesterol, LDL, triglycerides, increased HDL, prevention of hypertension, improved endothelial function, decreasing the incidence of metabolic syndrome and cardiovascular disease [25-27]. In relation to the control of bone loss, emotional well-being and self-esteem, regular physical activity and a healthy diet are basic tools, mainly for enabling better body image control, reducing many of the dissatisfactions and frustrations during this period [28]. In physical activity, some relaxation maneuvers can enhance and reduce climatic symptoms, especially vasomotor and sweating [29-30].

It is not believed that an emotionally adapted woman suffers great existential disturbances in the climacteric. MONTGOMERY (2010) [31] cites studies showing that in cultures where menopause is considered a natural phenomenon, women have fewer symptoms and anguish than in cultures where menopause is viewed negatively and implies the loss of women's roles and social status. It is possible, however, that the limitations imposed, and the insecurity determined by an exacerbated clinical picture due to a strong estrogen deficiency may unfavorably influence a woman's emotional state and interfere in family relationships, sexual adaptation and social integration [32,33]. In fact, there are many factors that are associated with menopausal depression, including health problems, marital problems, "empty nest" issues, financial difficulties, lack of physical exercise and environmental stresses, reinforcing the real need for psychological support throughout this phase $[34,35]$.

Some women associate the climacteric with old age, reproducing some negative meanings (prejudice, myths, fears) referring to this phase [36]. The mind influences every cell of our body; therefore, aging is fluid. It can accelerate, diminish, stop or even reverse [37]. Our beliefs and expectations influence the way we age [38]. Other individual factors can ease or complicate the crossing, for example, genetics, lifestyle, psychosocial conditions (satisfaction or not with work, marriage, family life), the existence of previous diseases such as thyroid dysfunction or depression. [39].

The imbalance often arrives in everyday life and is almost always not attributed to the arrival of the climacteric [40]. A multidisciplinary clinical view can contribute to the awareness, prevention and solution of various conflicts originated in this stage of life. Dialoguing about the biological, emotional, social and spiritual changes that occur with these women, as well as reflecting about the myths and insecurities about climacteria, will enable a new meaning to this phase. Therefore, it is necessary to understand and experience holistic assistance, considering their social, economic, cultural, educational, and emotional reality [41,42].

The reception, qualified listening, the formation of support groups and the closer relationship of health professionals with patients are fundamental tools in this context. In this way, the climate can be conducted with a "new look" for many women: a moment of rediscovery, of building new dreams and an instigating new beginning.

\section{References}

1. Johnson A, Roberts L, Elkins G (2019) Complementary and alternative medicine for menopause. J Evid Based Integr Med 24: 2515690X19829380. [Crossref]

2. Chiaramonte D, Ring M, Locke AB (2017) Integrative Women's Health. Med Clin North Am 101: 955-975. [Crossref]

3. Moreira AC, Silva AM, Santos MS, Sardao VA (2014) Phytoestrogens as alternative hormone replacement therapy in menopause: What is real, what is unknown. J Steroid Biochem Mol Biol 143: 61-71. [Crossref]

4. Gersh FL, Lavie C J (2020) Menopause and hormone replacement therapy in the 21st century. Heart 106: 479-481. [Crossref]

5. Lobo RA (2017) Hormone-replacement therapy: current thinking. Nat Rev Endocrinol 13: 220-231. [Crossref]

6. Daley AJ, Stokes-Lampard H, Thomas A, Rees M, Coleman S, et al. (2013) Aerobic exercise as a treatment for vasomotor menopausal symptoms: Randomised controlled trial protocol. Maturitas 76: 350-356. [Crossref]

7. Utian WH, Schiff I (2018) NAMS-Gallup survey on women's knowledge, information sources, and attitudes to menopause and hormone replacement therapy. Menopause 25 : 1172-1179. [Crossref]

8. Hart J (2019) Menopause: Shifting Hormones Linked to Anxiety and Depression Symptoms. Alternat Complement Therapies 25: 254-256.

9. Linn ES, Weyl L (2018) Hormone Replacement Therapy in Menopause. Springer, New York, NY, USA. pp: 231-245.

10. Peng W, Adams J, Sibbritt DW, Frawley JE (2014) Critical review of complementary and alternative medicine use in menopause: focus on prevalence, motivation, decisionmaking, and communication. Menopause 21: 536-548. [Crossref]

11. da Silva MG, Dias MS, Oliveira MP (2019) O período climatério sob ótica da mulher. Revista Saber Digital 12: 29-38.

12. Otani MAP, Barros NFD (2011) A Medicina Integrativa e a construção de um novo modelo na saúde. Ciência Saúde Coletiva 16: 1801-1811.

13. Maizes V, Rakel D, Niemiec C (2009) Integrative medicine and patient-centered care. Explore 5: 277-289. [Crossref]

14. Tonob D, Melby MK (2017) Broadening our perspectives on complementary and alternative medicine for menopause: A narrative review. Maturitas 99: 79-85. [Crossref]

15. Fan DM (2014) Holistic integrative medicine. Am J Digest Dis 1: 22-36.

16. Peng W, Sibbritt D, Steel A, Cramer H, Adams J (2019) Menopause and complementary and integrative medicine: A consideration of clinical evidence, grassroots use and contemporary clinical practice guidelines. Women's Health Complement Integrat Med pp: 12.

17. Pugliese G, Barrea L, Laudisio D, Aprano S, Castellucci B, et al (2020) What about the Mediterranean Diet as tool to Manage Obesity in Menopause? A Narrative Review. Nutrition: 110991. 
18. Noland D, Raj S (2019) Academy of nutrition and dietetics: revised 2019 standards of practice and standards of professional performance for registered dietitian nutritionists (Competent, Proficient, and Expert) in nutrition in integrative and functional medicine. J Academy Nutrit Dietetics 119: 1019-1036. [Crossref]

19. Kozakowski J, Gietka-Czernel M, Leszczyńska D, Majos A (2017) Obesity in menopause-our negligence or an unfortunate inevitability? Przeglad menopauzalny Menopause Review 16: 61. [Crossref]

20. Tucker L A, Fosson E, Bailey, BW, LeCheminant JD (2014) Is the dose-response relationship between body mass and hip bone mineral density in women influenced by diet, physical activity, or menopause? Am J Health Promotion 28: 325-327. [Crossref]

21. Wang Q, Ferreira DLS, Nelson SM, Sattar N, Ala-Korpela M, Lawlor DA (2018) Metabolic characterization of menopause: cross-sectional and longitudinal evidence. BMC Med 16: 1-12. [Crossref]

22. Kostecka M (2014) The role of healthy diet in the prevention of osteoporosis in perimenopausal period. Pakistan J Med Sci 30: 763. [Crossref]

23. Smith JR, Koepp KE, Berg JD, Akinsanya JG, Olson TP (2019) Influence of sex, menstrual cycle, and menopause status on the exercise pressor reflex. Med Sci Sports Exercise 51: 874-881.

24. Witkowski S, Serviente C (2018) Endothelial dysfunction and menopause: is exercise an effective countermeasure? Climacteric 21: 267-275.

25. Yafasova A, Mandrup CM, Egelund J, Nyberg M, Stallknecht B, et al (2019) Effect of menopause and exercise training on plasma apolipoprotein $\mathrm{M}$ and sphingosine-1phosphate. J Appl Physiol 126: 214-220. [Crossref]

26. Shimojo GL, Silva Dias DD, Malfitano C, Sanches IC, Llesuy S, et al (2018) Combined aerobic and resistance exercise training improve hypertension associated with menopause. Frontiers Physiol 9: 1471.

27. Grindler NM, Santoro NF (2015) Menopause and exercise. Menopause 22: 1351-1358.

28. Fontinele RG, Mariotti VB, Vazzoleré AM, Ferrão JSP, Junior JRK (2013) Menopause, exercise, and knee. What happens? Microsc Rese Technique 76: 381-387. [Crossref]

29. Portella CFS, Sorpreso ICE, de Assis ADSM, de Abreu LC, Junior JMS. et al (2020) Meditation as an approach to lessen menopausal symptoms and insomnia in working women undergoing the menopausal transition period: A randomized controlled trial. Advances Integrat Medic 26.
30. Sydora BC, Turner C, Malley A, Davenport M, Yuksel N, Shandro, T (2020) Can walking exercise programs improve health for women in menopause transition and postmenopausal? Findings from a scoping review. Menopause 27: 952-963. [Crossref]

31. Montgomery, M. (2010). Mulher: um projeto sem data de validade. In Mulher: um projeto sem data de validade pp: 269.

32. Namazi M, Sadeghi R, Moghadam ZB (2019) Social Determinants of Health in Menopause: An Integrative Review. Int J Women's Health 11: 637-647. [Crossref]

33. Soares CN (2019) Depression and Menopause: An Update on Current Knowledge and Clinical Management for this Critical Window. Med Clin North Am 103: 651. [Crossref]

34. Nazarpour S, Simbar M, Tehrani FR (2016) Factors affecting sexual function in menopause: A review article. Taiwan J Obstet Gynecol 55: 480-487. [Crossref]

35. Vivian-Taylor J, Hickey M (2014) Menopause and depression: is there a link? Maturitas 79: 142-146. [Crossref]

36. Freitas ER, Barbosa AJG (2015) Qualidade de vida e bem-estar psicológico no climatério. Arquivos Brasileiros de Psicologia 67: 112-124.

37. Erbil N (2018) Attitudes towards menopause and depression, body image of women during menopause. Alexandria J Med 54: 241-246.

38. Lipton BH (2007) A biologia da crença. Butterfly Editora

39. Parish SJ, Faubion SS, Weinberg M, Bernick B, Mirkin S (2019) The MATE survey: men's perceptions and attitudes towards menopause and their role in partners menopausal transition. Menopause 26: 1110. [Crossref]

40. Moore TR, Franks RB, Fox C (2017) Review of efficacy of complementary and alternative medicine treatments for menopausal symptoms. J Midwifery Womens Health 62: 286-297. [Crossref]

41. Ali AM, Ahmed AH, Smail L (2020) Psychological climacteric symptoms and attitude toward menopause among Emirati women. Int J Environ Res Public Health 17: 5028. [Crossref]

42. Zhang Y, Zhao X, Leonhart R, Nadig M, Wang J (2019) A cross-cultural comparison of climacteric symptoms, health-seeking behavior, and attitudes towards menopause among Mosuo Women and Han Chinese women in Yunnan, China. Transcult Psychiatry 56: 287-301. [Crossref]

Copyright: (C2020 Maiolino ABF. This is an open-access article distributed under the terms of the Creative Commons Attribution License, which permits unrestricted use, distribution, and reproduction in any medium, provided the original author and source are credited. 